\title{
Experiences of return to work after treatment for extremital soft tissue or bone sarcoma: Between distraction and leaving the disease behind
}

Sofia C. Zambrano, $\mathrm{PhD}^{1}$; Attila Kollár, $\mathrm{MD}^{2}$; Jürg Bernhard, $\mathrm{PhD}^{2}$

Short title: Return to work after sarcoma treatment

\section{Affiliations}

${ }^{1}$ University Centre for Palliative Care, Inselspital, Bern University Hospital, Bern, Switzerland

2Department of Medical Oncology, Inselspital, Bern University Hospital, Bern, Switzerland

Keywords: Cancer, Cancer survivors, Psycho-Oncology, Psychosocial issues, Return to work, Sarcoma, Oncology

\section{Corresponding author:}

Prof. Jürg Bernhard

Department of Medical Oncology, Inselspital, Bern University Hospital, Bern, Switzerland Tel: +41316324114 email: juerg.bernhard@insel.ch 


\begin{abstract}
Objective: We aimed to explore the return to work (RTW) experience of individuals in remission from extremital sarcoma.

Methods: Using a qualitative survey design, we asked sarcoma survivors about their RTW experiences after treatment. Seven men and eight women $(n=15), 43$ years old in average participated. The majority had soft tissue sarcoma $(n=14)$ and no amputations $(n=14)$. We analysed data thematically through an inductive approach.

Results: Participants' motivation to RTW and their experiences of this transition could be understood under the main theme of: 'searching for distraction and wanting to leave the disease behind', followed by 'problems of the new normal'. RTW was the next step after treatment, however being back at the same workplace/institution was challenging due to the interference of the effects of the disease and treatments, and peer perceptions. In other subthemes, we identified that RTW was facilitated by different 'signs of readiness', as well as by 'motivating factors and the meaning of having an occupation'.

Conclusions: Readiness to RTW while primarily an autonomous decision, can also be guided by third parties, including treating physicians. RTW can be challenging, since changes in performance as well as comments from peers become a constant reminder of the status prior to the illness. Given that RTW helps distract from the disease, these reminders can be confronting and highlight the role of health professionals and employers in preparing survivors and peers to facilitate the RTW.
\end{abstract}




\section{Background}

Advances in the prevention, early detection, and treatment of cancer have led to increased patient survival. ${ }^{1,2}$ As a result, return to work (RTW) has become a possibility and an expectation for those still at a working age.,4 Although the RTW experience of cancer survivors has been explored in general, ${ }^{5,15,16}$ the experience of people with specific and rare cancer diagnoses remains largely unexplored. ${ }^{6}$

One such disease is sarcoma, which represents $1 \%$ of all adult cancers, ${ }^{19}$ and whose treatment can leave patients with significant functional disabilities. ${ }^{12}$ The treatment of sarcoma at the localised disease stage is characterised by a wide surgical resection of the primary tumour. Because of the tumour location, which is most often found in the extremities, ${ }^{20}$ the treatment itself may impact directly the survivor's ability to RTW.

Furthermore, the psychological and social impact associated with the changes brought in by the disease and its treatment may differ from that of other cancer survivors.

Of the few available studies that have focused on general challenges and functional impairment in sarcoma survivors, ${ }^{17,18}$ insights into RTW only emerge as a side-product of the analysis. To date, only one study focused exclusively on the experience of RTW in sarcoma survivors, with a population largely comprised of very young adults who were studying or not gainfully employed. ${ }^{13}$ Thus, there is a paucity of data on adult sarcoma survivors who return to gainful employment and who are diagnosed at a not so young age.

Given that cancer patients are more likely to be unemployed than the general population, and that those diagnosed with sarcoma at an early stage can live productive lives (5-year survival rate of $85 \%),{ }^{7}$ we sought to identify what motivates survivors of extremital sarcoma to RTW. A deeper understanding of these motivations and experiences can help develop specific approaches to facilitate RTW. In this study, the term RTW includes return to a previous job, as well as to academic studies.

\section{Methodology}

\section{Design}

This study was part of a larger study about the predictors of RTW in disease-free adults with extremital sarcoma. Ethical approval was obtained (KEK 2016-01446). All participants provided consent.

\section{Procedure}

We employed a qualitative survey approach to data collection ${ }^{8}$ through an open-ended questionnaire containing five questions (Appendix 1) that we developed and pilot-tested. The questions focused on understanding the signs of readiness to RTW, perceived challenges, advantages, influence of the illness, and the meaning of RTW. In November 2017, participants received the questionnaire by post along with a reply-paid envelope. We did not send reminders after the initial send out. Data were collected until January 2018.

\section{Participants}

Patients surgically treated between 2000 and 2015 for limb sarcoma of soft tissue or bone at the sarcoma centre, Bern University Hospital, with an age at diagnosis of $\geq 18$ or $<65$ (age of retirement in Switzerland), alive and without evidence of disease were invited. Of the patients 
from the larger study, 21 were eligible for the qualitative study, since we targeted participants who were employed both before diagnosis and at the time of the study. Of those eligible, 15 completed the questionnaire ( $71 \%$ response rate). Participant characteristics appear in Appendix 2.

Analysis

The great majority of participants wrote thorough responses to each of the questions, allowing us to understand different facets of their experience. SCZ transcribed verbatim handwritten data, initially in German and then translated into English. JB checked translations for accuracy. From this point forward, to inform the analysis process, SCZ kept an audit trail with impressions about the data and preliminary findings.

We employed an inductive approach to thematic analysis ${ }^{11}$, using NVivo12. SCZ performed all initial analyses and discussed initial codes and impressions with JB, who was already familiar with the data and who reviewed the initial coding process. The process focused primarily on the semantic content of the data, taking a more realist approach ${ }^{11}$. We initially coded all transcripts per question, and later recoded all responses into more complex codes seeking deeper connections and patterns across the data (refer to Appendix 3 for a description of the theme development process). In the last stage, we further refined the themes through a process of constant comparison to determine the fit of the themes with the data as a whole. JB and SCZ reviewed and agreed on the final themes. Regarding saturation, although it was not a criterion to stop sampling due to our design, we achieved data saturation, evidenced by the redundancy of codes and preliminary themes when analysing the last surveys ${ }^{21}$. JB is a clinical psychologist and psycho-oncologist with experience in patients with sarcoma. SCZ is an experienced qualitative researcher with a psychology background and with research and clinical experience in palliative care.

Following Braun and Clarke's ${ }^{11}$ approach, we refrain from reporting frequencies, and instead employ terms such as 'minority', 'some', etc.

\section{Results}

Participants' motivation and experiences were broad but all had in common the 'search for distraction and wanting to leave the disease behind' as the main theme, followed by the 'problems of the new normal'. Participants' RTW was influenced by different 'signs of readiness' and by 'motivating factors and the meaning of having an occupation' (Appendix 4 contains a theme overview and additional quotes).

\section{'Searching for distraction and wanting to leave the disease behind'}

In the RTW experience, participants identified mostly positive consequences such as 'gaining distance from the illness' and 'gaining perspective in life and living consciously'. These consequences seemed to help them control the residual physical effects of the disease/treatment and any negative psychosocial impact on their daily life.

Gaining distance from the illness. RTW allowed participants to find a new normal by, to some extent, forgetting about the disease. Having to concentrate on their work tasks, and regaining social contact, allowed them to feel more control and to perceive themselves less as ill individuals. 
The distraction through work, the feeling of being needed and the appreciation of the whole environment made me forget my illness... Each activity distracted [me] from the consequences of the disease, such as from pain... (P1, male)

Gaining perspective in life and living consciously. The majority of participants mentioned that while RTW was a very important step in their recovery, they had also gained the realisation that life is more than work, and that they could negotiate limits and set priorities more easily now than before.

I have set other priorities and defined new goals for my (professional) life. I have become much more mature and thoughtful and I am better at dealing with provocation. I also am more careful with my time and think carefully about what it is worth 'wasting' time for and not. (P9, female)

Both women and men felt that they now established clearer boundaries to regain work-life balance.

Today it is easier for me to stop where I used to just keep going. No job is so important as to jeopardize health and well-being. (P2, male)

Through the illness experience, many participants became more conscious of being alive and thankful for the possibility of regaining the ability to move again.

I am certainly enjoying myself more consciously - especially the movement. I am very grateful that I am able to work under pressure... (P13, female)

Gaining perspective in life for a minority of participants was also about empathizing with the needs of others, particularly co-workers or patients, for those in a health profession.

I feel that I now have a new understanding for the co-workers I manage, if something similar should happen to them. (P15, female)

\section{The problems of the 'new normal'}

Oftentimes, returning to the same occupation/workplace was a reminder of who participants were before the illness, and thus they identified many challenges to their day-to-day life. Many of them were 'challenged by their own roles', by 'having to talk about the illness', by the 'perception of peers', and by 'becoming more aware of their own limitations'.

Being challenged by their own roles. All participants went back to the same occupation/workplace that they had before the illness. Having a before and after to compare with, meant that many of them perceived many tasks as more difficult or more stressful because of the changes caused by the illness or by the side-effects of the treatments.

I was mentally stressed more often and endured the children in the classroom worse. I also felt less resilient and reacted to noise and hustle with slight dizziness. (P15, female)

Some of the participants sought smaller changes to their roles such as working from home one day, while others needed more permanent changes, such as seeking to be retrained in a different occupation.

After almost a year it was difficult to work 8 hours a-day again. I found it difficult to work with full performance pressure all day long. Luckily, I had an understanding employer (and still have) who allows me one day a-week as a home office. (P2, male) 
Only one participant mentioned how differently she perceived her home-making activities from her occupation itself: dealing with work duties was not the issue, as was doing housework.

I was able to work $100 \%$ out of the house again, but there is no strength for the household. Housework doesn't count. (P6, female)

When their roles demanded the same posture for a prolonged time, such as sitting, and that position was no longer comfortable because of the sarcoma's location, it was perceived as a challenge.

Since my entire right thigh was affected by the therapy, I had (and still have) great difficulties sitting. Since I work on the computer all day it was difficult to sit in the same position all day. (P9, female)

Having to talk about the illness. Although many participants had missed the social interactions from work, which were helpful to regain normality, many of them were constantly confronted with questions about the disease. While returning to work allowed them to leave the disease behind, these questions made them uncomfortable, because they reminded them of the illness and their changed capacity.

A completely different challenge are all the colleagues who always ask about the state of health, which always reminds me of what was. (P9, female)

Being challenged by the perception of peers. Not only were participants confronted with having to talk about the illness with colleagues, but others also mentioned being surprised at their peers' lack of understanding of the effects of cancer in their ability to perform old tasks.

Where others go on and do more, I have to rest and take a break. The problem here is the lack of understanding from them (colleagues). ( $P 2$, male)

Other participants highlighted that being back at work seemed to give peers the impression that things were back at the point before the illness, and therefore peers did not understand that participants' lives had changed. In contrast, others were seen differently, which was also challenging, since they were perceived as weaker.

Employers and colleagues think you're healthy again. But it's nothing like before the disease, physically and psychologically you're not quite the same. (P6, female)

Becoming more aware and accepting of own limitations. Participants were very aware of how the illness had brought many limitations to their ability to do tasks that they could have easily performed in the past.

Some needed longer breaks, others needed to take things slowly, and others even had to look for different occupations where their limitations were not an impediment to their performance.

I didn't want to stay with my previous employer to avoid getting in the same treadmill again. The change was problematic because of the following circumstances: computer scientist, weakened by the disease and lack of self-confidence (I created a new job after this disease). Physically, it was not that easy. I needed longer breaks. (P2, male)

\section{Signs of readiness}

The majority of participants had interrupted work while they received surgical treatment, which for a minority included chemotherapy and radiotherapy. While for a minority there was no question of readiness, because they had had no interruptions, everybody else referred to 
signs of readiness in identifying when to RTW. This readiness was marked by not having significant disease and/or treatment related symptoms anymore, or when in exchange with a third party they felt ready to RTW.

Symptom-related readiness. The majority of participants felt ready to RTW when they stopped feeling pain, fatigue, nausea, and became stronger and had regained the ability to concentrate on different tasks.

Until then I didn't notice any more side effects of chemo, such as nausea or fatigue. (P4, female)

Treatment-related readiness. For some participants, waiting until all treatments were completed (surgeries, radiotherapy, chemotherapy,) was necessary before feeling ready to return to work. This also included waiting until scars had healed.

I never felt "really" ill and therefore it was clear to me as soon as the scar had healed that it would be normal to resume work. (P9, female)

Externally-negotiated readiness. The majority of the times, participants themselves established their readiness to RTW either out of necessity, in terms of earning a living, or in terms of leaving the disease behind. For a minority of participants however, the readiness was initially raised by a third party, such as the office in charge of the disability insurance.

(I was ready) when the IV (i.e. Swiss disability insurance) sent me to career counselling, (P10, male).

In other situations, it was through discussions with treating doctors or physiotherapists.

Together with the GP we discussed slowly (small workload) how to get back. (P6, female)

Accommodating employers often facilitated this readiness by allowing a transitioned work reentry.

I could start with $10 \%$ and work $10 \%$ more each month. My employer made this possible. (P14, female)

\section{Motivating factors and the meaning of RTW}

RTW was often facilitated by the wish of 'going back to structures and routines', 'selfimprovement', 'having a social impact on others', 'having contact with others', and 'securing an income and independence'.

Going back to structures and routines. During the illness and treatment, participants seemed to have little control over routines and daily structures. RTW meant regaining this control by knowing the content of their everyday life.

It was important to me to follow my regular working day as normally as possible and to give the illness as little space as possible in my life. (P9, female)

Having contact with others. Many participants highlighted the connection to others as a motivation to RTW. Although for some this meant having to talk about the disease, this social aspect of work allowed them to keep valuable connections. 
Having an impact on others. RTW was also a means to regain a place back in society and to actively contribute to it. Staying at home was thus not an option since participants wanted to make a difference to others through their occupation.

Having an activity means being useful (essential in our society) and having a value. Also

I'm a person who has to do something, sitting around doesn't suit me. It would be very difficult for me to be without work. ( $P 2$, male)

Self-improvement. Beyond the societal impact, RTW was often seen as an important part of one's identity. Participants saw the opportunity to grow as individuals through their occupation, and to constantly develop their skills.

In addition, I have the opportunity to face new challenges professionally and personally, and to develop myself further in this way. (P12, male)

Securing an income and financial independence. Although the majority of participants had access to good insurance schemes in their period of convalescence, many of them had the pressure to RTW, seeking to be financially independent. For those studying $(n=2)$, it meant completing their degrees and secure the opportunity to work in the future, while for all others it was about continuing to support themselves and/or their families financially.

There's also the pressure to be able to pay for the cost of living... Understandably, health insurance cannot continue to pay wages on a permanent basis. With the activity there was again a regular and secure income. ( $P 2$, male)

\section{Discussion}

Our study is one of the first to focus on the RTW experience of adult extremital sarcoma survivors. ${ }^{6}$ It is also one of the few but needed qualitative studies from the perspective of this particular group. ${ }^{12}$ Survivors in our study attached an important meaning to work, which may help understand why their decision to RTW was made rather autonomously. For our participants, work guarantees a secure income, but also represents an opportunity for selfimprovement, for contact with others, and importantly, it helps limit the presence of the disease in their daily life.

RTW however, can be challenging, since performance changes, as well as comments from peers, are constant reminders of the person before the illness. This tension experienced at work may make survivors' adjustment more difficult. The constant reminder of the self before the illness was named 'identity work' by Parsons et al. in their study of bone cancer survivors. ${ }^{13}$ Identity work seems an intrinsic part of RTW, and one that would need to be acknowledged by health professionals and employers when preparing survivors to RTW.

Perceptions from colleagues, which contributed to the difficulties in adjusting to the 'new normal' are important in terms of the need to prepare patients for these difficulties, but also in terms of developing strategies for workplaces to facilitate survivors' readjustment to work. Tjulin et al. ${ }^{14}$ highlight the need for workplaces to take into account social interactions and relations between workers, beyond a focus on the privacy and protection of employees and the legal responsibilities of employers. The employees themselves would need to be involved in devising a smoother transition into the workforce, and in a way prepare not only the survivor, but also their co-workers. 
Most patients with cancer seem to use the RTW as a way to return to prior known structures of everyday life. ${ }^{15}$ In our study, we identified a similar need of using work routines as a way to make life more predictable and to regain control. An important distinction was that after the illness experience, survivors sought to gain distance from work to limit its interference on their personal life. This way of seeing work as a means and not as an end was identified by Main et al. ${ }^{16}$ in a heterogeneous sample of cancer patients.

\section{Clinical implications}

In this study, the majority of participants determined their own readiness to RTW. In contrast to other malignant tumours, sarcomas are often located in the extremities, which are highly relevant to many occupations. Given the functional disability specific to sarcoma, a more difficult RTW transition would have been expected in this population. Our findings contradict this, as they largely agree with those reported in survivors from other types of cancer. ${ }^{5}$ Primary tumour site would thus seem to not impact RTW in those who successfully make the transition. In contrast, a study of survivors of sarcoma in the hip region found that RTW experiences were mostly negative. ${ }^{17}$ It may also be possible that because we focused on those who successfully RTW after treatment, that we missed the most negative experiences even within survivors of extremital sarcoma. Three to ten years after diagnosis, Fauske ${ }^{18}$ identified three different trajectories: back to normal, a new normal, and still struggling. While only 3 out of 18 participants experienced minor to no challenges, the great majority experienced some challenges adjusting to the new normal. In the same study, those still struggling, were the ones who had not RTW, therefore making them a group in which differences with other cancer survivors may be more evident. As sarcomas can be very heterogeneous entities, it is important for clinicians to distinguish the individual impact and interference of the sarcoma location on patients' disability and thus on their psychological and functional adjustment.Strategies to improve patients' ability to RTW should focus on multiple aspects fostering emotional, instrumental and social support. Intensified communication with medical staff, family members, friends and employers seem to be the cornerstone of a successful RTW process.

\section{Limitations}

We chose a qualitative survey approach ${ }^{10}$ mainly to limit participants' burden given the volume of data required for the main study. This approach prevented us from following up participants' responses with further questions, ${ }^{9}$ and although the majority provided long and comprehensive answers, allowing us to understand their experiences with good depth, it is possible that interviews could have yielded richer data. For example, our participants did not mention issues of body image, which may have been discussed if probed. On the other hand, the anonymity of the survey, may have allowed them to be more open about what is important from their own perspective. Similarly, our findings are based on a small sample size, limited to participants from a single institution. Interestingly, the few studies available about the general experience of sarcoma survivors, ${ }^{13,17,18}$ have similar sample sizes and have identified similar topics. Finally, although it may be possible that participants did not recall the more negative aspects of RTW because they participated in average 5 years after diagnosis, studies with longer periods, ${ }^{17,18}$ have still identified negative consequences, meaning that this recall effect may not have affected our study. 
Our study is one of the first to provide an insight into the experience of sarcoma survivors who RTW after treatment. Due to the paucity of research ${ }^{13}$, our results have helped identify further aspects of the experience of sarcoma patients when returning to work. Future studies could focus on survivors without an occupation before diagnosis and on those who are unable to RTW or who, after trying, decide to retrain or to seek a pension. Studying how sarcoma survivors reengage in hobbies and sports would also be of interest.

\section{Conclusion}

RTW in extremital sarcoma survivors can be challenging since changes in performance and comments from peers become a constant reminder of the status prior to the illness. Given that RTW helps distract from the disease, these reminders can be confronting. Our findings may help increase awareness and highlight the important role of health professionals and employers in preparing survivors and peers to facilitate RTW.

Acknowledgements: We thank the participants for sharing their experiences. We also thank Ms. Irene Reusser (study nurse) for her support preparing materials and in the recruitment process.

Conflict of interest statement: The authors have no conflict of interest to report

Data availability statement: Data are available from the corresponding author upon reasonable request.

Original publication statement: This manuscript contains original unpublished work. 


\section{References}

1. Siegel RL, Jemal A, Wender RC, Gansler T, Ma J and Brawley OW. An assessment of progress in cancer control. CA Cancer J Clin. 2018; 68: 329-39.

2. American Cancer Society. Cancer Facts \& Figures 2018. Atlanta: American Cancer Society, 2018.

3. Tang MH, Pan DJ, Castle DJ and Choong PF. A systematic review of the recent quality of life studies in adult extremity sarcoma survivors. Sarcoma. 2012; 2012.

4. De Boer AG, Taskila T, Ojajärvi A, Van Dijk FJ and Verbeek JH. Cancer survivors and unemployment: a meta-analysis and meta-regression. J Am Med Assoc. 2009; 301: 753-62.

5. Stergiou-Kita M, Pritlove C, Holness DL, et al. Am I ready to return to work? Assisting cancer survivors to determine work readiness. J Cancer Surviv. 2016; 10: 699-710.

6. Winnette R, Hess LM, Nicol SJ, Tai DF and Copley-Merriman C. The patient experience with soft tissue sarcoma: a systematic review of the literature. The PatientPatient-Centered Outcomes Research. 2017; 10: 153-62.

7. American Cancer Society. Cancer Facts \& Figures 2017: Special Section-Rare Cancers in Adults. Atlanta: American Cancer Society, 2017.

8. $\quad$ Braun V, Clarke V and Gray D. Innovations in qualitative methods. In: Gough B, (ed.). The Palgrave handbook of critical social psychology. London, UK: Palgrave, 2017, p. 243-66.

9. Braun V and Clarke V. Successful qualitative research: A practical guide for beginners. London: Sage, 2013.

10. Terry $\mathrm{G}$ and Braun V. Short but often sweet: The surprising potential of qualitative survey methods. Collecting qualitative data: A practical guide to textual, media and virtual techniques. Cambridge, UK: Cambridge University Press, 2017, p. 15-44.

11. Braun $\mathrm{V}$ and Clarke V. Using thematic analysis in psychology. Qualitative research in psychology. 2006; 3: 77-101.

12. McDonough J Eliott J, Neuhaus S Reid J and Butow P. Health-related quality of life, psychosocial functioning, and unmet health needs in patients with sarcoma: a systematic review. Psychooncology. 2019; Online first.

13. Parsons JA, Eakin JM, Bell RS, Franche RL and Davis AM. "So, are you back to work yet?" Re-conceptualizing 'work'and 'return to work' in the context of primary bone cancer. Soc Sci Med. 2008; 67: 1826-36.

14. Tjulin A, MacEachen E, Stiwne EE and Ekberg K. The social interaction of return to work explored from co-workers experiences. Disabil Rehabil. 2011; 33: 21-2.

15. Rasmussen DM and Elverdam $B$. The meaning of work and working life after cancer: an interview study. Psycho-Oncology. 2008; 17: 1232-8.

16. Main DS, Nowels CT, Cavender TA, Etschmaier M and Steiner JF. A qualitative study of work and work return in cancer survivors. Psychooncology. 2005; 14: 992-1004.

17. Fauske L, Bruland OS, Grov EK and Bondevik H. Cured of primary bone cancer, but at what cost: a qualitative study of functional impairment and lost opportunities. Sarcoma. 2015; 2015: 484196.

18. Fauske, L., Bondevik, H., Ahlberg, K., \& Bjørndal, A. Identifying bone sarcoma survivors facing psychosocial challenges. A study of trajectories following treatment. European journal of cancer care, 2019 e13119, first published 11 June 2019.

19. Siegel RL, Miller KD, Jemal A. Cancer statistics, 2015. CA: a cancer journal for clinicians. 2015;65(1):5-29.

20. von Mehren, M., Randall, R. L., Benjamin, R. S., Boles, S., Bui, M. M., Ganjoo, K. N., ... \& Keedy, V. Soft tissue sarcoma, version 2.2018, NCCN clinical practice guidelines in oncology. Journal of the National Comprehensive Cancer Network, 2018, 16(5), 536-563. 21. Sandelowski, M. and Given, L.M., 2008. The sage encyclopedia of qualitative research methods. Thousand Oaks, CA: SAGE Publications. 
Appendix 1. Questions and Instructions for questionnaire completion

Instructions: Please write down your feelings and experiences, in your own words, in the space below each of the questions. We invite you to write as much as you would like. If the space below the question is not enough, please write them at the reverse of the page, indicating which question you are expanding on.

Thank you for participating in our study!

1. How did you know that you were ready to go back to your occupation?

2. What do you think were the main challenges that you faced as you returned to your occupation and why?

3. What do you think are the main advantages of returning to an occupation and why?

4. How has the illness made an impact (positive or negative) since you returned to your occupation?

5. What does it mean for you to return to an occupation? 
Appendix 2. Participant characteristics

Characteristics

Age at diagnosis

Age at participation

Range: $27-55$ years

Range: $22-48$ years

36.0

42.7

\begin{tabular}{|c|c|c|}
\hline & & $\mathbf{N}(\%)$ \\
\hline \multirow[t]{2}{*}{ Gender } & Male & $7(46.6 \%)$ \\
\hline & Female & $8(53.3 \%)$ \\
\hline \multirow[t]{2}{*}{ Civil status before diagnosis } & Single & $7(46.6 \%)$ \\
\hline & Married & $8(53.3 \%)$ \\
\hline \multirow[t]{2}{*}{ Type of sarcoma } & Soft tissue & $14(93.3 \%)$ \\
\hline & Bone & $1(6.6 \%)$ \\
\hline \multirow{3}{*}{$\begin{array}{l}\text { Occupation at the time of } \\
\text { diagnosis }\end{array}$} & Employed & $12(93.3 \%)$ \\
\hline & Student & $2(13.3 \%)$ \\
\hline & Independent & $1(6.6 \%)$ \\
\hline \multirow[t]{2}{*}{ Histological sarcoma subtype } & Liposarcoma & $6(40 \%)$ \\
\hline & Other & $9(60 \%)$ \\
\hline \multirow[t]{2}{*}{ Tumour site } & Thigh & $9(60 \%)$ \\
\hline & Other & $6(40 \%)$ \\
\hline \multirow[t]{2}{*}{ Procedure in surgical intervention } & Limb salvage & $14(93.3 \%)$ \\
\hline & Amputation & $1(6.6 \%)$ \\
\hline \multirow[t]{3}{*}{ Other treatments } & Radiotherapy & $7(46.6 \%)$ \\
\hline & Chemotherapy & $2(13.3 \%)$ \\
\hline & $\begin{array}{l}\text { No } \\
\text { radiotherapy/chemotherapy }\end{array}$ & $6(40 \%)$ \\
\hline
\end{tabular}



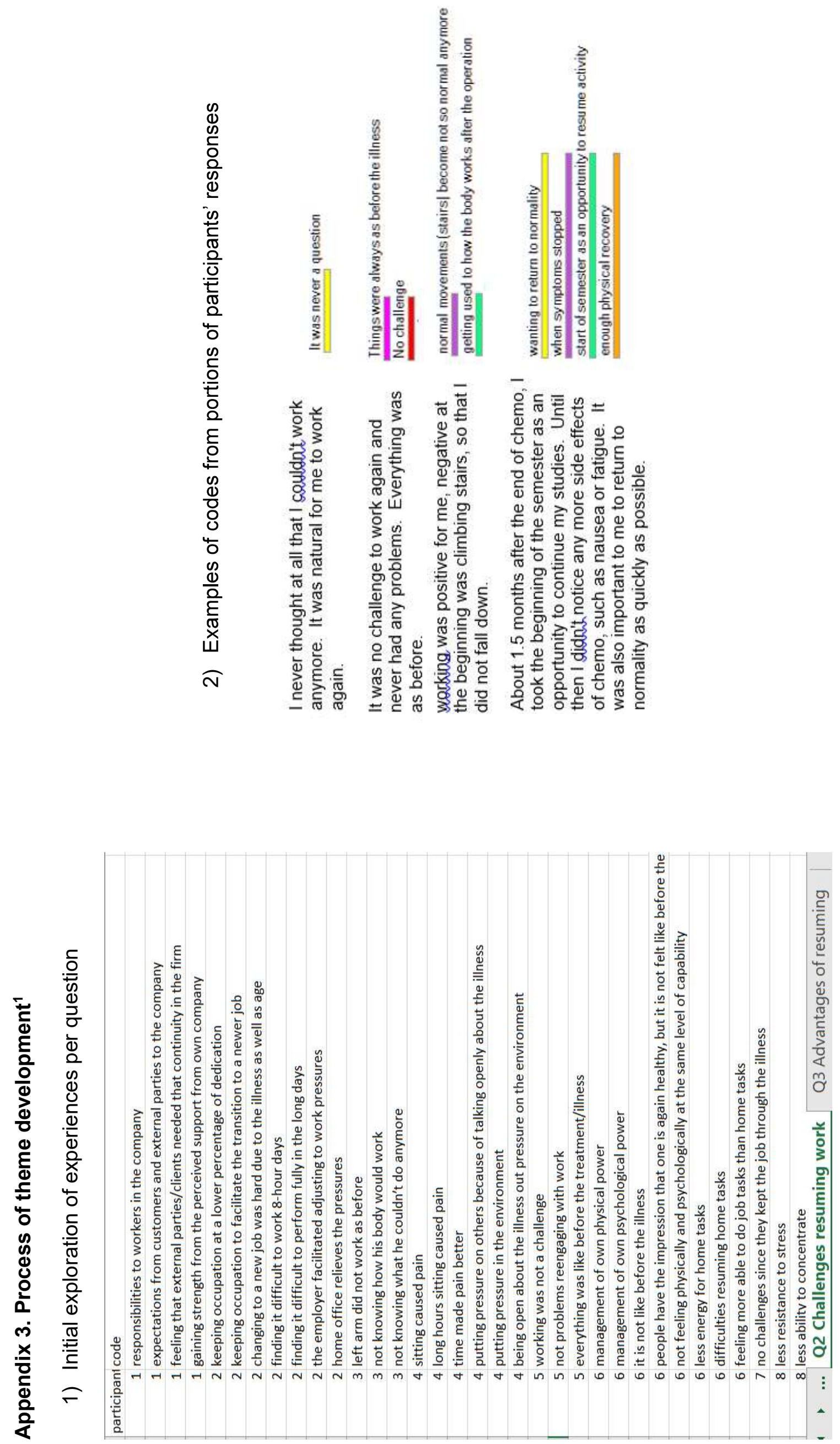

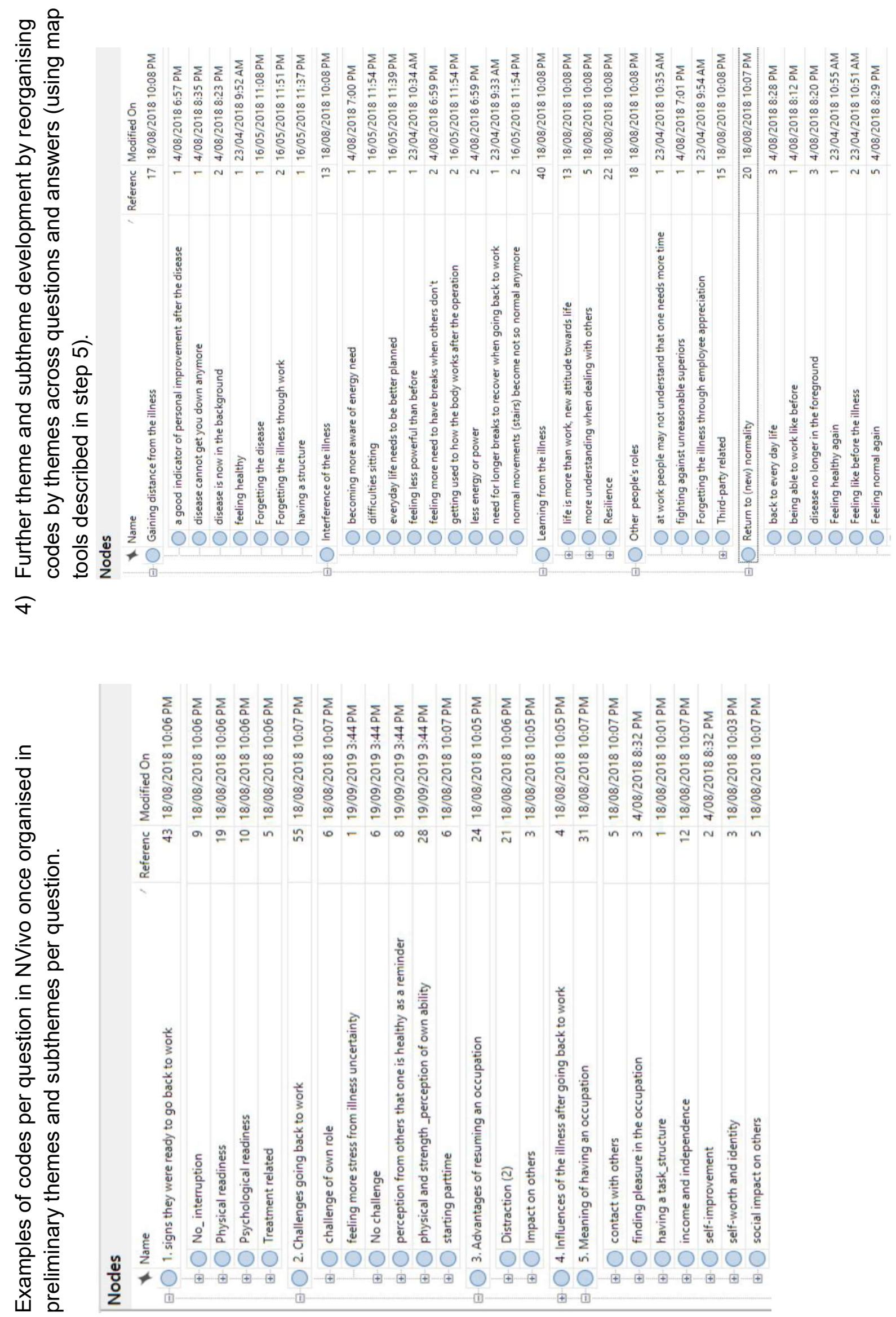


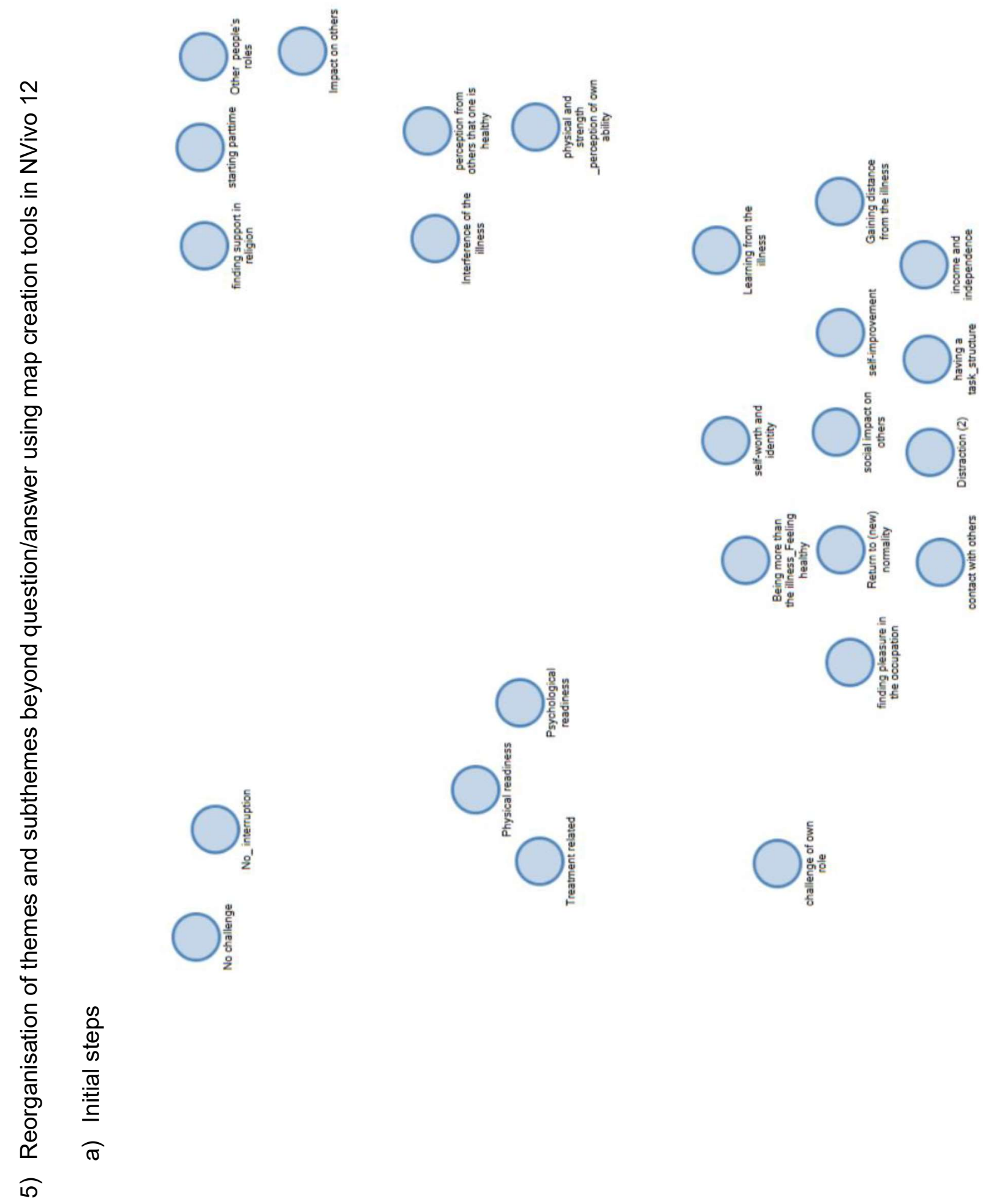




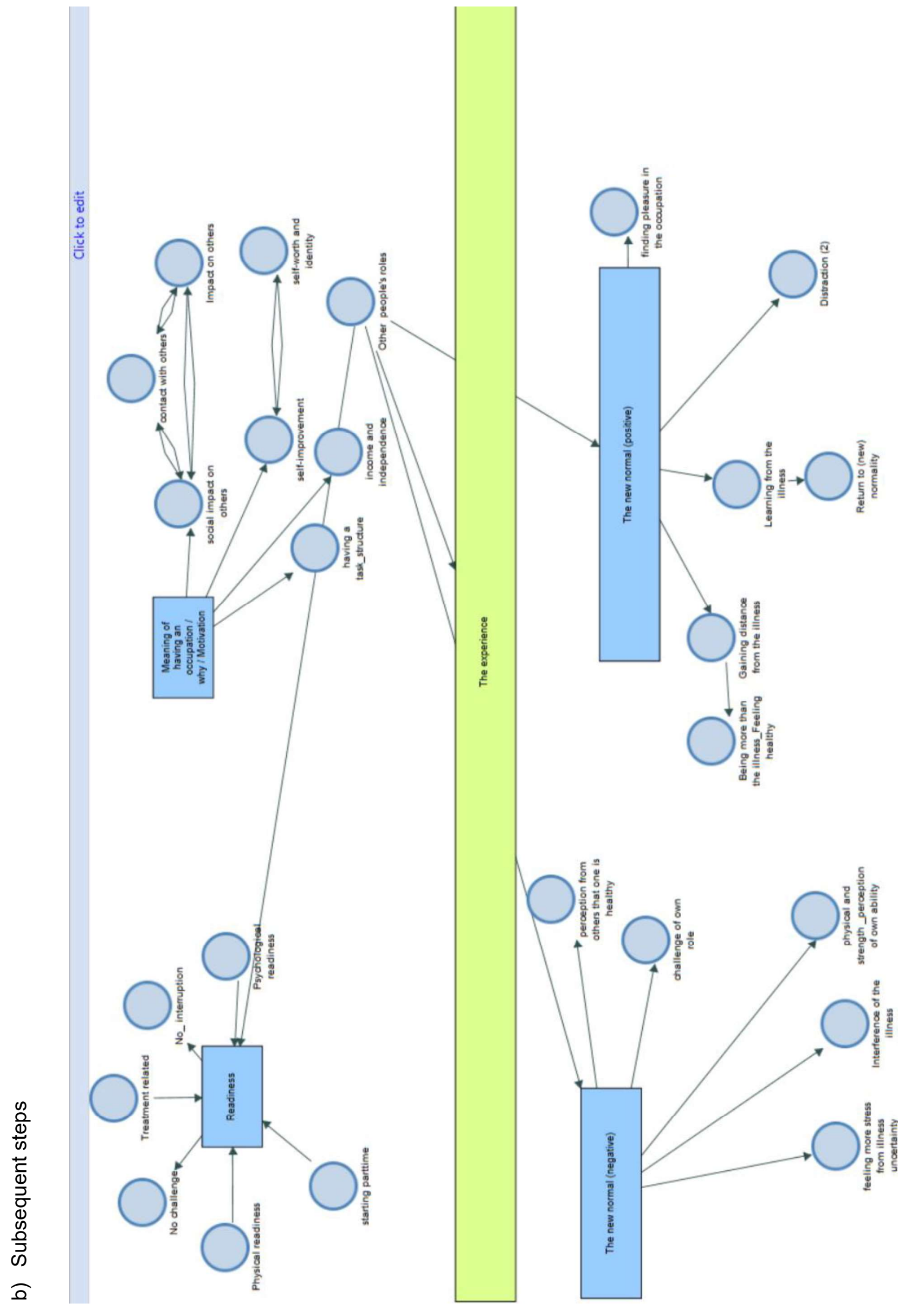


Appendix 4. Themes/Subthemes Overview and additional illustrative quotes

\begin{tabular}{|c|c|c|}
\hline \multirow{2}{*}{$\begin{array}{l}\text { Searching for } \\
\text { distraction and } \\
\text { wanting to } \\
\text { leave the } \\
\text { disease behind }\end{array}$} & $\begin{array}{c}\text { Gaining distance from the } \\
\text { illness }\end{array}$ & $\begin{array}{l}\text { My studies again challenged me mentally and } \\
\text { physically, I was no longer forced to sit at home } \\
\text { with "my illness". (Participant } 4, \text { female) } \\
\text { [and advantage] is the focus on professional } \\
\text { challenges as a contrast to focusing on the } \\
\text { illness. Since the resumption of activity, the } \\
\text { disease is in the background... (Participant 12, } \\
\text { male) }\end{array}$ \\
\hline & $\begin{array}{l}\text { Gaining perspective in } \\
\text { life and living consciously }\end{array}$ & $\begin{array}{l}\text { I am now mainly in the oncological field with a } \\
\text { slightly different attitude towards patients. } \\
\text { (Participant } 4 \text {, female) } \\
\text { The illness has given me a different attitude to } \\
\text { life. I am happier and more relaxed. My work is } \\
\text { important but not the most important. } \\
\text { (Participant } 3 \text {, female) }\end{array}$ \\
\hline \multirow{4}{*}{$\begin{array}{l}\text { The problems } \\
\text { with the 'new' } \\
\text { normal }\end{array}$} & $\begin{array}{c}\text { Being challenged by their } \\
\text { own roles }\end{array}$ & $\begin{array}{l}\text { I have fought for a new focus in my activity with } \\
\text { conditions that are better adapted to the } \\
\text { reserves of energy that I have left at the time; I } \\
\text { have become more aware of the slightly reduced } \\
\text { endurance and the greater dependence on } \\
\text { breaks. (Participant } 8 \text {, male) } \\
\text { (...) Physically, however, it was not that easy to } \\
\text { return to work. I needed very long breaks. } \\
\text { (Participant } 1 \text {, male) }\end{array}$ \\
\hline & $\begin{array}{c}\text { Having to talk about the } \\
\text { illness }\end{array}$ & $\begin{array}{l}\text { The biggest challenges were to get back in } \\
\text { touch with many people and answer many } \\
\text { questions about my illness. (Participant } 14 \text {, } \\
\text { female) }\end{array}$ \\
\hline & $\begin{array}{l}\text { Being challenged by the } \\
\text { perception of peers }\end{array}$ & $\begin{array}{l}\text { I also found this a challenge: how other people } \\
\text { perceived me differently, less able than before } \\
\text { the illness. (Participant } 9, \text { female) }\end{array}$ \\
\hline & $\begin{array}{l}\text { Becoming more aware } \\
\text { and accepting of own } \\
\text { limitations }\end{array}$ & $\begin{array}{l}\text { I now have to accept that everything goes a little } \\
\text { slower or differently than before the illness. } \\
\text { (Participant 10, male) } \\
\text { Since my entire right thigh was affected by the } \\
\text { therapy, I had (and still have) great difficulties } \\
\text { with sitting. (...) I cannot sit on high chairs (e.g. } \\
\text { bar stools) with 'sharp' edges that press directly } \\
\text { onto the wound. (Participant } 9 \text {, female) }\end{array}$ \\
\hline
\end{tabular}

Signs of readiness
Symptom-related readiness
[I knew I was ready] because the postoperative pain steadily decreased, and the walking distance 


\begin{tabular}{|c|c|c|}
\hline & & $\begin{array}{l}\text { and resilience improved. Also, because I could } \\
\text { stand well. (Participant 13, female) } \\
\text { As the strength increased and fatigue decreased. } \\
\text { (Participant } 10, \text { male) }\end{array}$ \\
\hline & $\begin{array}{l}\text { Treatment-related } \\
\text { readiness }\end{array}$ & $\begin{array}{l}\text { Since I did not require any serious surgery and no } \\
\text { follow-up treatment, I never had the discussion } \\
\text { that I would be unable to work for a longer period. } \\
\text { As soon as the scar healed, I became a teacher } \\
\text { again. (Participant } 15, \text { female) }\end{array}$ \\
\hline & $\begin{array}{l}\text { Externally-negotiated } \\
\text { readiness }\end{array}$ & $\begin{array}{l}\text { The positive reactions of the attending physicians } \\
\text { to my physical and mental condition encouraged } \\
\text { me to continue. (Participant } 1, \text { male) }\end{array}$ \\
\hline \multirow{5}{*}{$\begin{array}{l}\text { Motivating } \\
\text { factors and } \\
\text { meaning of } \\
\text { returning to } \\
\text { work }\end{array}$} & $\begin{array}{c}\text { Going back to structures } \\
\text { and routines }\end{array}$ & $\begin{array}{l}\text { I'm a person who has to be occupied with } \\
\text { something, sitting around doesn't suit me. It would } \\
\text { be very difficult for me to be comfortable without } \\
\text { work. (Participant } 2 \text {, male) } \\
\text { I would have gotten too bored without it. Although } \\
\text { I was a bit physically limited at the beginning, I did } \\
\text { not feel ill at all and wanted to lead a normal life } \\
\text { again. (Participant } 4 \text {, female) }\end{array}$ \\
\hline & Self-improvement & $\begin{array}{l}\text { Work is an important part of my identity, my } \\
\text { constant development, my social life, my } \\
\text { aspiration to take care of myself. (Participant } 8 \text {, } \\
\text { male) } \\
\text { For me, the job is a central part of my life. I like } \\
\text { working because I can develop myself further and } \\
\text { constantly challenge myself anew. I can't imagine } \\
\text { not doing any work. (Participant 15, female) }\end{array}$ \\
\hline & Having an impact & $\begin{array}{l}\text { An activity gives me meaning, fulfilment. I have a } \\
\text { part in other people's lives, I am part of society. } \\
\text { (Participant } 13, \text { female) }\end{array}$ \\
\hline & Having contact & $\begin{array}{l}\text { I looked forward to having contact with other } \\
\text { employees and customers, as well as participation } \\
\text { in company events. (Participant } 1, \text { male) }\end{array}$ \\
\hline & $\begin{array}{l}\text { Securing an income and } \\
\text { financial independence }\end{array}$ & $\begin{array}{l}\text { Having a job is very important for me, because the } \\
\text { economic livelihood of the family also depends on } \\
\text { it. (Participant 12, male) } \\
\text {...There is no income without work. (Participant 2, } \\
\text { male) }\end{array}$ \\
\hline
\end{tabular}

